\title{
[gw22-e1041] CORRELATION OF THE PREGNANCY-ASSOCIATED \\ PLASMA PROTEIN-A GENE IVS6+95 POLYMORPHISM WITH THE SERUM PAPP-A LEVEL IN PATIENTS WITH ACUTE MYOCARDIAL INFARCTION
}

Guoping He, Fengjie Liu Department of Cardiology, Affiliated Wujin Hospital of Jiangsu University, Changzhou, China

10.1136/heartjnl-2011-300867.114

Objective To investigate the association between PAPP-A gene IVS6+95 polymorphism and the serum level of PAPP-A in patients with AMI from the Chinese Han population of Sunan region.

Methods Fifty-six patients with AMI (AMI group) and 51 control subjects who were free from coronary artery disease confirmed by coronary angiography (control group) were recruited into the study. The PAPP-A gene IVS6+95 polymorphism was determined by polymerase chain reaction and restriction fragment length polymorphism analysis (PCR-RFLP). The serum level of PAPP-A were determined by enzyme-linked immunosorbent assay (ELISA).

Results As compared with those in the control group, the frequencies of the CC genotype in AMI group was higher $(11.8 \%$ vs $28.6 \%, p=0.032)$ and the frequencies of the CG ( $41.2 \%$ vs $32.1 \%)$ and GG (47.1\% vs $39.3 \%)$ genotype, and C allele $(35.3 \%$ vs $48.2 \%$ ) was not different (all $\mathrm{p}$ value $>0.05$ ). Multivariate logistic regression analysis showed that there was significant correlation of the CC genotype $(\mathrm{OR}=3.382$, $95 \%$ CI 2.798 to $3.966, p=0.037)$ and $\mathrm{C}$ allele $(\mathrm{OR}=2.093$, $95 \%$ CI 1.753 to $2.443, p=0.030$ ) with the risk of AMI, The serum level of PAPP-A (M/IOR) was significantly higher in AMI group $(8.59 / 148.91 \mathrm{pg} / \mathrm{ml})$ than that in the control group $(0.05 / 14.42 \mathrm{pg} / \mathrm{ml})(\mathrm{p}<0.001)$. No significant differences were found in the serum level of PAPP-A among any of the genotypes of the PAPP-A gene IVS6+95 within AMI group and its subgroup (the same gender group and the same age group), and control group, respectively (all $p$ value $>0.05$ ), suggesting no association of the PAPP-A gene IVS6+95 polymorphism with the serum level of PAPP-A. Multiple linear regression analysis showed that the serum level of PAPP-A was not associated with $\mathrm{CHD}$-associated factors such as age, gender, smoking, history of diabetes mellitus and hypertension, and dislipidemia in AMI group. Conclusion: In the Chinese Han population of Sunan region, there is the IVS6+95 polymorphism of PAPP-A gene, which may be associated with attack of AMI but not associated with the serum level of PAPP-A; the serum PAPP-A level is significantly increased and not affected by CAD relevant factors in patients with AMI, which suggest that there is an association of the serum level of PAPP-A with unstable plaque and may be an independent risk factor for attack of AMI. 